\title{
Frequency of the High Body Mass Index in School Going Children in Dhaka City
}

\author{
LAMISA SAIYARA SIDDIQUE ${ }^{1}$, SAMSUN NAHAR ${ }^{2}$, TANJIMA PARVIN ${ }^{3}$
}

\author{
${ }^{1}$ Medical student, International Medical University, Malayasia, ${ }^{2}$ FCPS (Medicine), MD Cardiology student (III part ) \\ Department of Cardiology, ${ }^{2}$ Bangabandhu Sheikh Mujib Medical University Dhaka, ${ }^{3}$ Assistant Professor, Department of \\ Cardiology, Bangabandhu Sheikh Mujib Medical University Dhaka \\ Address of Correspondence: Lamisa Saiyara Siddique, Medical student, International Medical University, Malayasia, \\ E-mail: lamisa.saiyarasiddique@student.imu.edu.my
}

\begin{abstract}
:
Childhood obesity is highly prevalent in urban areas of Bangladesh but information is limited. The aim of this study was to find out the prevalence of obesity in children aged 9-11 years and raise awareness about obesity and its complications. The study was conducted in a Private English Medium school in Dhaka involving 140 students whose height and weight was measured. The BMI was calculated by software provided by Centre of Disease Control. In the present study, we showed that $50 \%$ of the students were either overweight or obese out of which 26.4\% were obese. Majority of those found obese or overweight consumed fast foods. In conclusion, prevalence of obesity was high in a private school, which houses children from mostly middle to high income families. Enforcing healthy eating habits amongst parents could yield better results in lowering the BMI. Further surveillance in this population is essential in verifying the impact of obesity.
\end{abstract}

\section{Introduction:}

Obesity is one of the most serious public health problems. ${ }^{1}$ It has become a global pandemic. Obesity is defined as an excessive accumulation of body fat ${ }^{2}$ and childhood and teens whose BMI for age is in the $95^{\text {th }}$ percentile or higher are considered obese. ${ }^{3}$ WHO has defined childhood obesity as one of the most serious public health challenges of the $21^{\text {st }}$ century and right fully so. ${ }^{4}$ According to a recent report, out of an estimated 43 million obese children worldwide in 2010 , approximately $81 \%$ were from developing countries, half of which (18 million) were reported to be living in Asia despite of huge burden of under-nutrition. By 2020, it is estimated that the global prevalence of childhood obesity will reach approximately 60 million.$^{5}$ The prevalence of childhood obesity has increased greatly during the past two to three decades in developed countries. With industrialization and urbanization, obesity is now becoming widely prevalent in developing countries as well. ${ }^{6}$ Childhood obesity is the result of persistent adverse changes in food intake, life style and energy expenditure. Obese children and adolescents are at increased risk of having type 2 diabetes or impaired glucose tolerance, mixed features of type 1 and type 2 diabetes, hypertension, dislipidaemia, fatty liver disease, metabolic syndrome, psychosocial complications, obstructive sleep apnoea, orthopaedic problems, polycystic ovarian syndrome etc. ${ }^{5}$ This study focused on prevalence and risk factors for obesity in a private school in Dhaka.

\section{Methods and materials:}

This study was carried out in a private English Medium School in Dhaka city which have been selected by lottery. Like other private schools, it houses children from mostly middle to high income families. The children aged between 9-11 years were included. A questionnaire was made and children's height, weight, their diet and lifestyle were recorded. A total of 140 students were a part of this study.

\section{Anthropometric measurements}

\section{Height (cm)}

The measurements of standing height by using appropriate scales with minimal cloths. Height was measured by using a portable, locally manufactured, stadiometer, standing upright on a flat surface without shoes. The position of the eyes and ear lobes was horizontal, feet was together, knees straight and heels, buttocks and shoulders blades was in contact with vertical surface of anthrop meter. Arms were hanging loosely at the sides with palm facing the thighs. The head was not necessarily in contact with the vertical surface; it may be necessary to hold the heels to ensure that they did not leave the ground. Subjects were asked to take a breath and stand erect to aid the straightening of the spine. Shoulders were relaxed. Height was recorded to the nearest $\mathrm{cm}$. If the reading fell between two values, the lower reading was recorded. 


\section{Weight (kg)}

The balance was placed on a hard flat surface and checked and adjusted for zero balance before each measurement. The subjects were stood in the center of the platform, look straight ahead and wearing light cloths without shoes. Weight was recorded to the nearest $0.1 \mathrm{~kg}$.

\section{BMI}

Calculating body mass index by dividing weight in $\mathrm{kg}$ by square height in meters.

BMI $=$ Weight $(\mathrm{Kg}) /$ Height $(\mathrm{m})^{2}$

The BMI of the children was calculated by software provided by the Centre of Disease Control. Children and teens whose BMI for age is -

- In the $95^{\text {th }}$ percentile or higher are considered obese.

- Between the $85^{\text {th }}$ and less than the $95^{\text {th }}$ percentile are considered overweight.

- Between the $5^{\text {th }}$ and less than the $85^{\text {th }}$ percentile are considered normal weight.

- Below the $5^{\text {th }}$ percentile are considered underweight.
Statistical analysis was performed using SPSS package 16.0. Categorical data was expressed in percentage or number .Parametric data was evaluated by student $t$ test .Categorical data was evaluated by Chi square test .Significance was defined by $\mathrm{p}$ value $<0.05$.

\section{Results}

A total of 140 students were included in this study .Table 1 shows the demographic background of the survey participants. Of the study population $73 \%$ were male and $67 \%$ were female. According to survey $47.1 \%$ of the students had normal BMI, 2.9\% were underweight and the remaining $50 \%$ were either overweight or obese, out of which 26.4\% were obese. Age specific prevalence of BMI was high in male compared to female (Table 2) .Majority 91(65\%) students consumed fast food and most of them were overweight or obese (Table 3). The association between consumption of fast food and overweight or obese is statistically significant $(\mathrm{p}<0.001)$. Table $4 \&$ Table 5 showed no influence of sports activities and duration of sleep on high BMI .

Table-I

Demographic and outcome variable

\begin{tabular}{lccc}
\hline Variables & Categories & Frequency & Percent \\
\hline Sex & Male & 73 & 52.1 \\
& Female & 67 & 47.9 \\
Eating fast food & Yes & 91 & 65.0 \\
& No & 49 & 35.0 \\
Sports activities & Yes & 98 & 70.0 \\
& No & 42 & 30.0 \\
Duration of sleep & $<8$ hrs & 86 & 61.4 \\
\hline
\end{tabular}

Table-II

Prevalence of high BMI

\begin{tabular}{|c|c|c|c|c|c|c|}
\hline & \multicolumn{2}{|c|}{$\begin{array}{c}\text { Male } \\
(\mathrm{n}=73)\end{array}$} & \multicolumn{2}{|c|}{$\begin{array}{l}\text { Female } \\
(\mathrm{n}=67)\end{array}$} & \multicolumn{2}{|c|}{$\begin{array}{c}\text { Total } \\
(\mathrm{n}=140)\end{array}$} \\
\hline & No & $\%$ & No & $\overline{\%}$ & No & $\%$ \\
\hline $\begin{array}{l}\text { Under weight } \\
\text { ( }<5 \% \text { ile) }\end{array}$ & 1 & 1.4 & 3 & 2.9 & 4 & 2.9 \\
\hline $\begin{array}{l}\text { Normal BMI } \\
\left.\text { ( } 5^{\text {th }}-85^{\text {th }} \% \text { ile }\right)\end{array}$ & 23 & 31.5 & 43 & 47.1 & 66 & 47.1 \\
\hline $\begin{array}{l}\text { Overweight or obese } \\
\text { (85 } 85^{\text {th }} \text { ile) }\end{array}$ & 23 & 31.5 & 10 & 23.6 & 33 & 23.6 \\
\hline Obese (95 $\%$ thile) & 26 & 35.6 & 11 & 16.4 & 37 & 26.4 \\
\hline
\end{tabular}


Table-III

Relation between BMI and food habits

\begin{tabular}{|c|c|c|c|c|c|}
\hline & \multicolumn{4}{|c|}{ Fast food } & \multirow[t]{3}{*}{ P value } \\
\hline & \multicolumn{2}{|c|}{ Yes (91) } & \multicolumn{2}{|c|}{ No (49) } & \\
\hline & $\bar{n}$ & $\overline{\%}$ & $\bar{n}$ & $\%$ & \\
\hline $\begin{array}{l}\text { Under weight } \\
\text { (<5\%ile) }\end{array}$ & 1 & 1.09 & 3 & 6.1 & \\
\hline $\begin{array}{l}\text { Normal BMI } \\
\text { (5 } 5^{\text {th}}-85^{\text {th }} \% \text { ile) }\end{array}$ & 27 & 29.7 & 39 & 79.6 & 0.001 \\
\hline $\begin{array}{l}\text { Overweight } \\
\text { (85 \%ile) }\end{array}$ & 30 & 32.9 & 3 & 6.1 & \\
\hline Obese(95 $95^{\text {thoile})}$ & 33 & 36.3 & 4 & 8.2 & \\
\hline
\end{tabular}

$\mathrm{P}$ value reached from chi square test

Table-IV

Relation between BMI and sports activities

\begin{tabular}{|c|c|c|c|c|c|}
\hline & \multicolumn{4}{|c|}{ Sports activities } & \multirow[t]{3}{*}{ P value } \\
\hline & \multicolumn{2}{|c|}{ Yes (98) } & \multicolumn{2}{|c|}{ No (42) } & \\
\hline & $\mathrm{N}$ & $\%$ & $\mathrm{n}$ & $\%$ & \\
\hline $\begin{array}{l}\text { Under weight } \\
\text { (<5\%ile) }\end{array}$ & 2 & 2.0 & 2 & 4.8 & \\
\hline $\begin{array}{l}\text { Normal BMI } \\
\text { (5 } 5^{\text {th}}-85^{\text {th }} \% \text { ile) }\end{array}$ & 45 & 45.9 & 20 & 47.6 & 0.821 \\
\hline $\begin{array}{l}\text { Overweight } \\
\text { (85 \%ile) }\end{array}$ & 24 & 24.5 & 9 & 21.4 & \\
\hline Obese(95\%\%ile) & 27 & 27.6 & 11 & 26.2 & \\
\hline
\end{tabular}

$\mathrm{P}$ value reached from chi square test

Table-V

Relation between BMI and duration of sleep

\begin{tabular}{|c|c|c|c|c|c|}
\hline & \multicolumn{4}{|c|}{ Duration of sleep } & \multirow[t]{3}{*}{ P value } \\
\hline & \multicolumn{2}{|c|}{$<8$ hrs (86) } & \multicolumn{2}{|c|}{$>8$ hrs (54) } & \\
\hline & $\mathrm{N}$ & $\%$ & $\mathrm{n}$ & $\%$ & \\
\hline Under weight & 2 & 2.3 & 2 & 3.7 & \\
\hline Normal BMI & 40 & 46.5 & 25 & 46.2 & 0.964 \\
\hline Overweight & 20 & 23.3 & 13 & 24.1 & \\
\hline Obese & 24 & 27.9 & 14 & 25.9 & \\
\hline
\end{tabular}

$\mathrm{P}$ value reached from unpaired t- test

\section{Discussion}

In our study the prevalence of obesity and overweight among school children of 9 to 11 year olds were $26.4 \%$ and $23.6 \%$ respectively. A study conducted amongst school children in Dhaka aged between 3 to 18 years of age, found $17.9 \%$ obese and $23.6 \%$ overweight children and adolescents . ${ }^{7}$ The available data from the other South East Asian showed the similar rate of obesity among school aged children ${ }^{8}$ This study revealed, more boys were both overweight and obese compared to girls among 9 to 11 year olds. A cross sectional survey in Lebanon showed prevalence of childhood obesity much higher in boys (7.5\%) than the girls (3.2\%) among 3 to 19 year olds . ${ }^{9}$ In 
USA, boys were more at risk for overweight than the girls among 6 to 19 year olds. ${ }^{10}$ Majority of those found obese or overweight consumed junk food in this study. A crosssectional study was performed on 541 children (273 boys and 268 girls) aged 6-7 years, in urban and rural areas of South-East Serbia found more obese children in urban areas than the rural areas. This difference ascribed to more sweets and fast food consumption and spending time in watching TV among the urban children compared to rural children. ${ }^{11}$

\section{Conclusion}

The present findings indicate that obesity is increasing steadily and stealthily in Bangladesh. Obesity is a serious problem which requires immediate attention and raising awareness amongst the children, parents and teachers. School plays a vital role in curbing obesity .Physical exercise must be made compulsory in all schools and annual sports day should be arranged so that children strive harder to become more active. Schools should take the initiative to measures the students BMI every year and counsel the parent's. Thus effective strategies should be developed to halt the epidemic.

\section{Reference:}

1. Janssen I, Katzmarzyk PT, Boyce WF, Vereecken C et al. Comparison of overweight and obesity prevalence in schoolaged youth from 34 countries and their relationships with physical activity and dietary patterns. Obesity Review 2005: 6 (2):123-32.
2. Lohman T.G. The use of skin folds to estimate body fatness on children and youth. Journal of Physical Education, Recreation \& Dance 1987; 58(9): 98-102.

3. Statistical sourcebook. Understanding childhood obesity. American Heart Association2011.3.

4. World Health Organization: Childhood overweight and obesity on the rise: Global Strategy on Diet, Physical Activity and Health. 2004.

5. de Onis M, Blossner M, Borghi E: Global prevalence and trends of overweight and obesity among preschool children. Am J Clin Nutr 2010, 92(5):1257-1264.

6. Mohsin F, Begum T, Azad K, Nahar N. An Overview of Childhood Obesity. Birdem Med J 2012; 2(2): 93-98.

7. Tyyeb S, Baki A, Sarker S, Zabeen B, Begum T, Azad K, Nahar N. Prevalence of obesity among affluent school children in Dhaka. Mymensingh Med J. 2010; 19(4):549-554.

8. Jafar TH, Qadri Z, Islam M, Hatcher J, Bhutta ZA, Chaturvedi $\mathrm{N}$.Rise in childhood obesity with persistently high rates of undernutrition among urban school-aged Indo-Asian children. Arch Dis Child 2008. 93(5):373-378.

9. Sibai AM, Hwalla N, Adra N, Rahal B. Prevalence and covariates of obesity in Lebanon: findings from the first epidemiological study. Obes Res 2003, 11(11):1353-1361.

10. Hedley AA, Ogden CL, Johnson CL, Carroll MD, Curtin LR, Flegal KM .Prevalence of overweight and obesity among US children, adolescents, and adults, 1999-2002. JAMA: J Am Med Assoc 2004, 291(23):2847-2850.

11. Stojanovic D, Belojevic G. Prevalence of obesity among children aged 6-7 years in South-East Serbia. Obes Rev 2009, 10(3):262-264. 